\title{
Active and Passive Immunization Against Staphylococcus aureus Periprosthetic Osteomyelitis in Rats
}

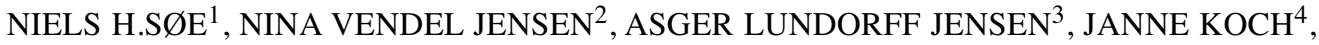 \\ STEEN SEIER POULSEN ${ }^{5}$, GERALD B. PIER ${ }^{6}$ and HELLE KROGH JOHANSEN ${ }^{7,8}$ \\ ${ }^{1}$ Hand Section, Department of Orthopaedics, ${ }^{2}$ Department of Anaesthesiology, \\ Intensive Care and Operations, Herlev and Gentofte University Hospital, Hellerup, Denmark; \\ ${ }^{3}$ Biochemical Department, Faculty of Life Science, University of Copenhagen, Copenhagen, Denmark; \\ ${ }^{4}$ Department of Experimental Medicine, Faculty of Health Science, University of Copenhagen, Copenhagen, Denmark; \\ ${ }^{5}$ Biomedical Department, Panum Institute, University of Copenhagen, Copenhagen, Denmark; \\ ${ }^{6}$ Division of Infectious Diseases, Department of Medicine, \\ Brigham and Women's Hospital, Harvard Medical School, Boston, MA, U.S.A.; \\ ${ }^{7}$ Department of Clinical Microbiology, Rigshospitalet, Copenhagen University, Copenhagen, Denmark; \\ ${ }^{8}$ The Novo Nordisk Foundation, Center for Biosustainability, Technical University of Denmark, Hфrsholm, Denmark
}

\begin{abstract}
Background/Aim: Staphylococcus aureus infection associated with orthopedic implants cannot always be controlled. We used a knee prosthesis model with implantrelated osteomyelitis in rats to explore induction of an effective immune response with active and passive immunization. Materials and Methods: Fifty-two SpragueDawley rats were divided into active $(N=28)$ and passive immunization groups $(\mathrm{N}=24)$. A bacterial inoculum of $10^{3} \mathrm{~S}$. aureus MN8 was injected into the tibia and the femur marrow before insertion of a non-constrained knee prosthesis in each rat. The active-immunization group received a synthetic oligosaccharide of polysaccharide poly- $N$-acetylglucosamine (PNAG), 9GlcNH $\mathrm{H}_{2}$ and the passive-immunization group received immunization with immunoglobulin from rabbits infected with $S$. aureus. Results/Conclusion: Active immunization against PNAG significantly reduced the consequences of osteomyelitis infection from $P N A G$ producing intercellular adhesion (ica ${ }^{+}$but not ica $S$. aureus. Passive immunization resulted in better clinical assessments in animals challenged with either ica ${ }^{+}$or ica S. aureus, suggesting a lack of specificity in this antiserum.
\end{abstract}

This article is freely accessible online.

Correspondence to: Niels H. Søe, Hand Section, Department of Orthopaedics, Gentofte University Hospital, Niels Andersensvej 65, 2900 Hellerup, Denmark. E-mail: Niels.Soee.Nielsen@regionh.dk

Key Words: Osteomyelitis, implant-related infection Staphylococcus aureus, immunization, vaccine, ica ${ }^{+}$strain, ica $^{-}$strain .
Infections associated with indwelling orthopedic devices can be difficult to cure without removing the device, and therefore expensive to manage (1). Although common infection-control measures, such as laminar air flow in operating theatres and administration of systemic antimicrobial prophylaxis, are beneficial, they have not completely eliminated orthopedic implant-related infections (2). In recent decades, there has been a dramatic increase in Staphylococcus aureus infections, particularly of those expressing resistance to multiple antibiotics, throughout the community (3). S. aureus is the predominant pathogen associated with infected metal implants (4). Although at least nine new antimicrobial agents targeting $S$. aureus have been approved since 2000 (5), there is concern that $S$. aureus will acquire additional drug-resistance mechanisms that will circumvent the effectiveness of antibiotics (6). Additionally, because $S$. aureus infections cannot always be prevented by prophylactic administration of commonly-used antibiotics in the surgical setting, other preventative strategies are needed (7).

A $S$. aureus vaccine is one potential mechanism to boost the immune system that could eradicate the infecting microbe. Because many of the individuals most susceptible to staphylococcal infections are the least competent to mount an effective immune response, active as well as passive immunization strategies must be explored (8-10), as well as combinations of vaccination and antibiotic treatments (11). Another strategy is to find infection-resistant implant materials (12).

Our previous study in rats indicated that an inoculum of $10^{3}$ colony forming units (CFU) of the $S$. aureus MN8 strain gave reproducible signs of osteomyelitis when injected into rat tibias and femurs along with implantation of a knee prosthesis, including loosening of the implant after 2 weeks of infection 
(13). Inocula of $>10^{4} \mathrm{CFU}$ induced massive osteomyelitis and most of the prostheses were completely displaced. A bacterial inoculum of $10^{2} \mathrm{CFU}$ led to no signs of osteomyelitis. Deletion of the 4-gene ica-abcd operon encoding the proteins needed for synthesis of the conserved cell surface polysaccharide poly- $N$-acetyl glucosamine (PNAG) had a minor effect on virulence in implant-related osteomyelitis.

In the present study, we report on findings in rats with implanted knee prosthesis infected with $10^{3} \mathrm{CFU}$ of $i \mathrm{ca}^{+} S$. aureus $\mathrm{MN} 8$ following active vaccination against the PNAG antigen using a synthetic oligosaccharide-protein conjugate vaccine under development for human use. We also evaluated the impact of passive immunization, using antiserum obtained from a goat injected with the same vaccine, against implantassociated infection with both $i c a^{+}$and $i c a^{-} S$. aureus MN8.

\section{Materials and Methods}

Experimental design. Fifty-two male Sprague-Dawley rats, 7-9 weeksold (Taconic Europe) with a weight of about $300 \mathrm{~g}$ were used for these experiments. Rats were divided into active ( $\mathrm{n}=28$ at start, two postsurgical deaths, 26 evaluable cases) and passive immunization groups ( $\mathrm{n}=24$ at start, three post-surgical deaths, 21 evaluable cases). Rats were infected with $10^{3} \mathrm{CFU}$ of PNAG-producing (ica $\left.{ }^{+}\right)$wild-type $S$. aureus $\mathrm{MN} 8$ or an isogenic mutant with deletion of the ica genes (ica::tet), referred to as the $i c a^{-}$strain. The rats received the bacterial inoculations into the marrow of the tibia and femur before insertion of a non-constrained knee prosthesis. Each group $(n \geq 5)$ had a matched control group $(n=4-8)$. Animals were clinically and radiographically followed for 2 weeks and then sacrified using an intracardiac injection of $2 \mathrm{ml}$ of $200 \mathrm{mg}$ pentobarbital $/ \mathrm{ml}$. Histological and microbiological analysis were then carried out.

The animal protocols were approved by the Animal Ethics Committee of Denmark (2005/561-1049 and 2012-15-2934-00684). All the animal studies were carried out at The Panum Institute the University of Copenhagen, under supervision of a veterinarian.

Immunization procedure. Actively immunized controls received sodium chloride $(\mathrm{NaCl})$ subcutaneously and passively immunized controls received normal goat serum intraperitoneally. The activeimmunization group received cutaneous injections of a $10 \mu \mathrm{g} / \mathrm{dose}$ of a synthetic PNAG oligosaccharide, $9 \mathrm{G} 1 \mathrm{cNH}_{2}$, conjugated to tetanus toxoid (9GlcNH2-TT), previously described (14), 3, 2 and 1 week before implantation of the prostheses. The passive immunization group received immune or normal antisera intraperitoneally on days $-3,0,3,6,9$ and 12 , where day 0 was the day of operation.

S. aureus strains and infection process. We used the MN8 strain of $S$. aureus originally obtained from a patient with toxic shock syndrome $(15,16)$. Each rat was injected with $10 \mu$ l containing $10^{3}$ CFU of $\mathrm{ica}^{+}$or $\mathrm{ica}^{-}$S. aureus strain MN8 into the medullary canals of the femur and tibia. The suspension was injected into the marrow hole and after that the condylar prosthesis was inserted.

Operative procedure, materials required and anesthesia. All rats were sedated with a subcutaneous injection of hypnorm/dormicum $0.3 \mathrm{ml} / 100 \mathrm{~g}$ given preoperatively and re-administered every 15 minutes at $0.15 \mathrm{ml} / 100 \mathrm{~g}$.
The skin over the left knee was sterilized twice with alcohol. The fur was shaved with a razor. The knee was opened with a parapatellar medial incision and the tendon with the patella was dislocated laterally. The articulating cartilage was osteotomized with bone scissors from the distal femur and the proximal tibia inclusive of the menisci and cruciate ligaments protecting the collateral ligaments. A $2 \mathrm{~mm}$ wide and a $10 \mathrm{~mm}$ deep hole was bored into the femur and tibia with a hand drill to fit the joint components. A ratsized, in-house designed and produced non-constrained knee prosthesis was used. The joint capsule and skin were closed with Ethibond 4-0 and Vicryl 50 after placement of the knee prosthesis, a press-fit model, without bone cement (13).

After the operation, a femoralis block of the operated extremity was placed below the inguinal ligament using 1\% lidocaine/0.5\% bupivacaine in $1 \mathrm{ml}$.

Radiographic evaluation. Front and lateral X-ray images were taken on days 0 (operation), 7 and 14. In order to assess development and progression of bone infection, the modified scoring system of An $e t$ al. (17) was used. The scoring system uses radiographic evaluation of infected bone grading the involved bone for periosteal reaction, osteolysis, soft-tissue swelling, deformity, sequestrum formation, spontaneous fracture and general impression.

Clinical evaluation. Body weight, temperature and well-being of the animal were monitored by a veterinarian.

Microbiological evaluation. After sacrifice, the prosthesis components were explanted and rolled over non-selective solid media (5\% Danish blood agar and chocolate agar plates; State Serum Institute, Copenhagen, Denmark) and then cultured. Isolated bacteria were identified as previously described (18) and the plates scored for growth as follows: growth in the first streak: 1, growth in the first two streaks: 2, and growth in all three streaks: 3 .

Bone and soft-tissue histology. After removal of the prosthesis, the remnants of the tibia, femur and synovialis were fixed in $4 \%$ buffered paraformaldehyde and decalcified in $10 \%$ formic acid for 7 days in EDTA. Samples were then embedded in paraffin, and transverse sections of $5 \mu \mathrm{m}$, including the implantation site, were cut on a microtome. The sections were stained using hematoxylineosin. Semiquantitative scoring of all specimens was performed blind by a pathologist who was not aware of the treatment groups (SSP9). For histological scoring of severity of inflammation, transverse sections of the tibia and femur (with the prosthesis removed) and tissue from the synovialis were investigated. Each of the three tissues (femur, tibia, and synovialis) was given a score ranging from 0 to 4 , depending on the severity of inflammation. 0 meant no signs of inflammation, 1 was slight focal accumulation of inflammatory cells (neutrophils), 2 was moderate but consistent inflammation in the transverse sections or moderate inflammation of the entire circumference around the cavity after prosthesis removal, 3 was the start of formation of an abscess in the cavity, and 4 was abscess formation and destruction of bone material with the synovialis completely infiltrated by neutrophils. The scores from the three separate tissues were added, giving a maximum score of 12 .

Biochemical analysis. Alpha-(1)-acid glycoprotein (AGP) (normal range $=0-130 \mathrm{ng} / \mathrm{ml})$, an acute-phase protein, was measured on days 0 (preoperative), 7 and 14 (19). 
Data analysis. Due to the small number of animals per group, the discrete nature and narrow range of the measurements, it was chosen not to perform statistical analyses.

\section{Results}

Microbiological results. In the actively-immunized group, a decrease in bacterial numbers in the $i c a^{+}$group immunized against PNAG compared to the control was achieved as seen from the microbiological score shown in Figure 1. In the PNAG-immune rats challenged with the $\mathrm{ica}^{-}$strain there was a similar decrease. Among passively immunized rats, the antiPNAG serum resulted in decreased bacterial levels, compared to controls given normal goat serum, regardless of whether they were infected with $i c a^{+}$or $i c a^{-} S$. aureus. For mice with antibody to PNAG, the mean microbiological score was threefold in the $i c a^{+}$group compared to the $i c a^{-}$group but lower than that in the $i \mathrm{ca}^{+}$control group, although the same as that for the $i c a^{-}$controls.

Biochemistry. All data appeared to show an effect of active immunization against the $\mathrm{ica}^{+}$strain. In the passively immunized group, there was an effect in groups challenged with either the $i \mathrm{ca}^{+}$or $i \mathrm{ca}^{-}$strain compared to the control group receiving normal goat serum after 1 and 2 weeks. The basis for the apparent specificity of protective effects following active immunization against PNAG for the PNAGproducing strain is clear. The apparent lack of specificity for the effect of the anti-PNAG-immune serum on both PNAG and non-PNAG-expressing $S$. aureus is less clear, it may be that this serum has antibodies to multiple $S$. aureus antigens active against both $\mathrm{ica}^{+}$and $i \mathrm{ca}^{-}$strains.

$X$-Ray examination. The radiological analysis showed signs of an effect in both actively and passively immunized groups, with a minimum factor of 2 (Figure 1).

Histopathological findings. Infiltration by inflammatory cells was clearly observed around the prosthesis (Figure 2A and D) in all control groups. There was a decrease in inflammation in both immunized groups (Figure $2 \mathrm{~B}, \mathrm{C}$ and $\mathrm{E}$ ), where mean scores were clearly lower in the $\mathrm{ica}^{+}$actively immunized group and in the $i c a^{-}$passively immunized group (Figure 1).

Clinical results. There were no apparent differences in mean weight loss between the immunized and the control groups. All prostheses were in situ with loosening in the control groups. No deep wounds around the knees were seen in any animals of any group.

\section{Discussion}

This in vivo animal study of both active and passive immunization showed that the strongest effects on the
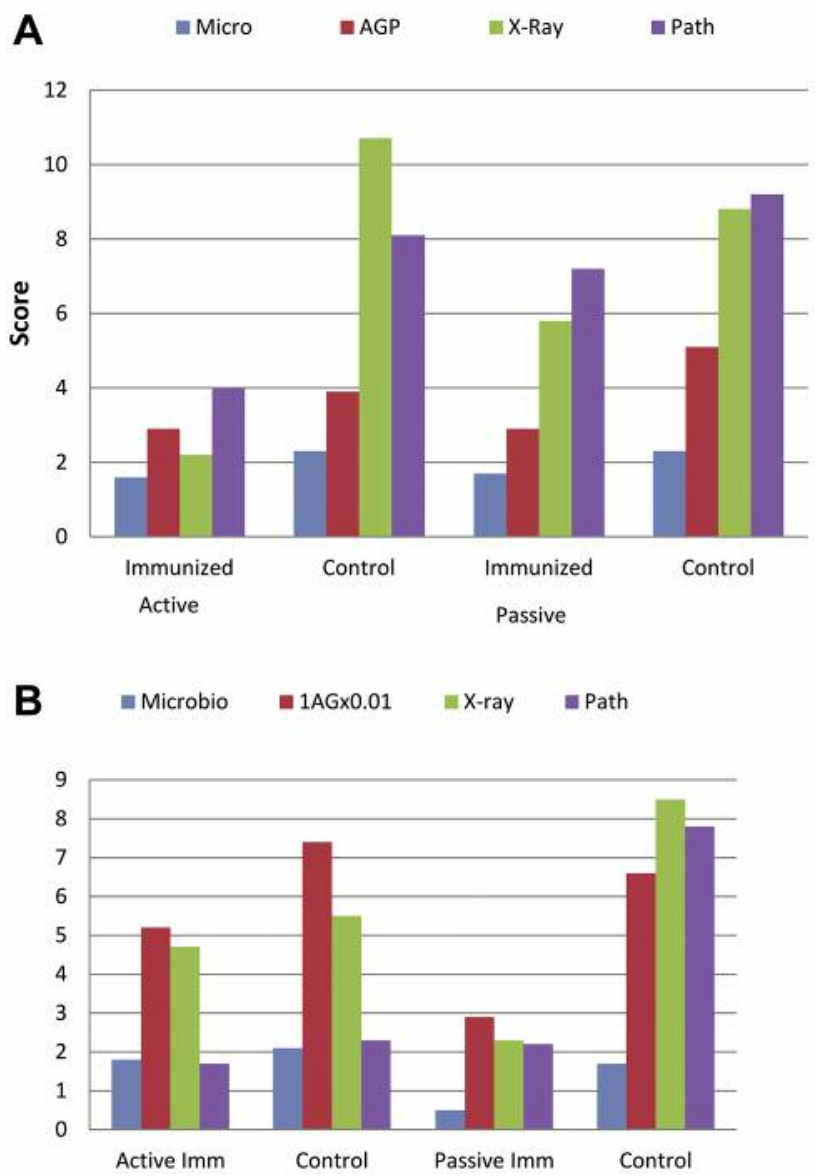

Figure 1. A. ica ${ }^{+}$bacteria: The intercellular adhesion (ica) locus is present in Staphylococcus aureus and represents biofilm formation. $B$. ica- bacteria: the strains are characterized as negative for the biofilm formation.

parameters measured were seen in rats actively immunized with a vaccine to induce a protective antibody against PNAG that were then challenged with an $\mathrm{ica}^{+}$PNAG-producing strain of $S$. aureus. When compared to non-immune control groups, lower AGP levels (reflecting microbiologic burden), $\mathrm{x}$-ray scores and pathology scores were achieved by immunizing against PNAG and challenging with a wild-type, $\mathrm{ica}^{+}$strain. Passive immunization had a less pronounced effect on the $\mathrm{ica}^{+}$strain, with a more pronounced effect on the PNAG-negative $S$. aureus variant. This is most readily explained by the presence of antibodies to multiple $S$. aureus antigens in the passively administered immunoglobulin obtained from an immunized goat. These would be expected to be effective against ica $^{-} S$. aureus. The greater effect of the post-infection goat antiserum on the $\mathrm{ica}^{-}$strain compared to the $\mathrm{ica}^{+}$strain suggests that the presence of the PNAG antigen on the bacterial surface reduces the efficacy of the antibodies against the non-PNAG antigens on the bacterial surface. 

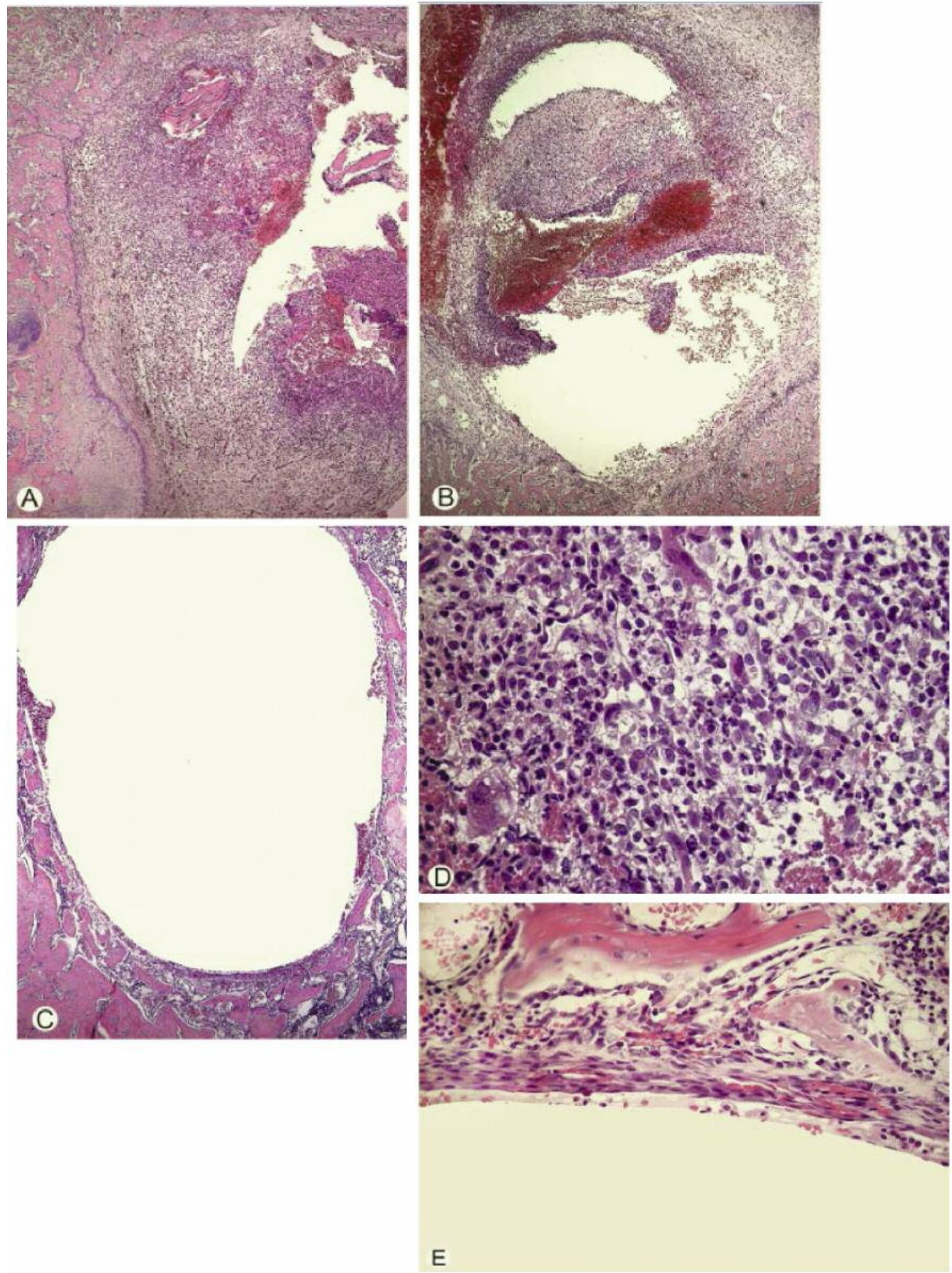

Figure 2. A: Extensive inflammatory exudate in the femur cavity from an unimmunized control rat. B: Slightly less inflammation in the femur marrow in a rat passively immunized. C: The cavity of the femur from a rat from the group actively immunized showing almost no inflammation. D: Higher magnification of the inflammatory exudate depicted in (A), showing heavy infiltration of inflammatory cells including polymorphonuclear leucocytes in the femur marrow. E: Higher magnification of area from $(C)$, showing almost total absence of inflammatory reaction at the surface of the cavity where the implant is positioned. Stain: Hematoxylin-eosin. 
PNAG, also known as intercellular adhesion polysaccharide (20), is a surface polymer produced by both $S$. aureus and $S$. epidermis, and many other pathogens (21). PNAG promotes biofilm formation and enhances staphylococcal virulence in mouse infection models $(12,22)$. In other studies, investigators immunized mice, rabbits and goats with either native PNAG, containing $>90 \%$ acetate substituents on the amino groups in the glucosamine molecule, or dPNAG, wherein the acetate substitution is $<20 \%$, conjugated to diphtheria toxoid (20). This study and another (22) indicated that antibodies to dPNAG, but not native PNAG, are opsonic and provide protection against experimental $S$. aureus infection. Additional studies using synthetic oligosaccharides of PNAG and dPNAG conjugated to carrier proteins confirmed the need to use only non-acetylated glucosamines for vaccination to achieve protective immunity $(14,21)$, most likely via opsonic killing of bacteria. Thus, numerous investigations have consistently found an effect on infection and disease when opsonic antibody to PNAG is present due to either active or passive immunization (23-25).

In our study, we saw significant protection against the $\mathrm{PNAG}^{+}$strain for the actively immunized group, with scores of 2-3, representing minimal infection and pathology, for all parameters. With the $\mathrm{PNAG}^{-}$strain, we saw a reduction in measured parameters compared to controls but not to the same degree as seen with the $\mathrm{PNAG}^{+}$strain. It is not surprising that a vaccine targeting the PNAG antigen is much less effective when the $i c a^{-}$gene is missing. This diminished effect is indicative of the specificity of the protection induced by vaccination.

Other preclinical animal studies revealed that mice immunized with a recombinant form of an adhesin, which mediates $S$. aureus binding to fibrinogen and promotes the attachment to biomaterial surfaces (26), reduced arthritis and lethality induced by $S$. aureus. However, protection was straindependent (27). Another study described a monoclonal antibody for inhibiting the effects of the accessory gene regulator (agr) of virulence in $S$. aureus (28). The monoclonal antibody reduced the expression of the effector molecule of the agr system, AgrC, and protected against infection. Another group showed that a monoclonal antibody to $S$. aureus glucosaminidase protects against implant-associated infections (25). In our study, we saw a significant effect on the various parameters in the rats passively immunized with antibody to PNAG and challenged with the $i c a^{-} S$. aureus strain when compared to the control group. The effect on the $i \mathrm{ca}^{-}$strain is somewhat difficult to evaluate as only four control animals given normal goat serum were available for analysis.

The animal model is suitable for reliably inducing implant osteomyelitis. Active immunization was shown to markedly reduce the consequences of infection from $\mathrm{ica}^{+} S$. aureusinduced osteomyelitis. Passive immunization with a mixture of antibodies to multiple $S$. aureus antigens gave a notable effect in both the $i c a^{+}$and $i c a^{-}$groups and it seems that the effects observed might be statistically significant if more animals were included in the study. Choosing appropriate antigens to include in an immunization strategy is a major challenge in creating a staphylococcal vaccine. Immunization based on only a single virulence determinant could have limited efficacy because of the multifactorial nature of the pathogenesis of staphylococcal infection. A number of $S$. aureus vaccines composed of inactive toxins or their subunits have been evaluated pre-clinically (29). The value of adding toxin components to multicomponent prophylactic vaccine formulation is unresolved. Overall, an effective vaccine for $S$. aureus-induced osteomyelitis should include candidate antigens that are surface exposed and expressed by most of the clinical $S$. aureus strains.

In developing vaccines against $S$. aureus, both active and passive immunization approaches should be pursued, as these are not mutually exclusive and may well turn out to be complementary.

\section{Conflicts of Interest}

The Authors alone are responsible for the content and writing of this article. The Authors report the following conflicts of interest: Niels H.Søe, Nina Vendel Jensen, Asger Lundorff Jensen, Janne Koch, Steen Seier Poulsen, Helle Krogh Johansen: No conflict Gerald B. Pier is an inventor of intellectual properties [human monoclonal antibody to PNAG and PNAG vaccines] that are licensed by Brigham and Women's Hospital to Alopexx Vaccine, LLC, and Alopexx Pharmaceuticals, LLC, entities in which GBP also holds equity. As an inventor of intellectual properties GBP also has the right to receive a share of licensing-related income (royalties, fees) through Brigham and Women's Hospital from Alopexx Pharmaceuticals, LLC, and Alopexx Vaccine, LLC. GBP's interests were reviewed and are managed by the Brigham and Women's Hospital and Partners Healthcare in accordance with their conflict of interest policies.

\section{Acknowledgements}

The Authors thank Technician Ulla Johansen, Rigshospitalet, Denmark, Technician Lise Lotte Corneliussen, State Serum Institute, Denmark, and Frank Espersen, MD, Denmark.

The Novo Nordisk Foundation supported HKJ through a clinical research stipend.

\section{References}

1 Darouiche RO: Treatment of infections associated with surgical implants. N Engl J Med 350(14): 1422-1429, 2004

2 Darouiche RO: Antimicrobial approaches for preventing infections associated with surgical implants. Clin Infect Dis 36: 1284-1289, 2003

3 Rivera AM and Boucher HW: Current concepts in antimicrobial therapy against select Gram-positive organisms: methicillinresistant Staphylococcus aureus, penicillin-Resistant pneumococci and vancomycin-resistant enterococci. Mayo Clin Proc 86: 12301243, 2011. 
4 Eron LJ: Prevention of infection following orthopaedic surgery Antibiot Chemother 33: 140-164,1985.

5 Rai J, Randhawa GK and Kaur M: Recent advances in antibacterial drugs. Int J Appl Basic Med Res 3: 3-10, 2013.

6 de Lancastre H, Oliveira D and Tomaz A: Antibiotic resistant Staphylococcus aureus: a paradigm of adaptive power. Curr Opin Microbiol 10: 428-435, 2007.

7 Parvizi J, Alijanipour P, Barberi EF, Hickok NJ, Philips KS, Shapiro IM, Schwarz EM, Stevens MH, Wang Y and Shirtliff ME: Novel developments in the prevention, diagnosis and treatment of periprosthetic joint infections. J Am Acad Orthop Surg 23: 32-43, 2015.

8 Deresinski S: Anti-staphylococcal vaccines and immunglobulins: current status and future prospects. Drugs 66: 1797-1806, 2006.

9 Otto M: Targeted immunotherapy approaches for staphylococcus infections: focus on anti-MSCRAMM antibodies. BioDrugs 22: 27-36, 2008.

10 Skurnik D, Merighi M, Grout M, Gadjeva M, Maira-Litran T, Ericsson M, Goldmann DA, Huang SS, Datta R, Lee JC and Pier GB: Animal and human antibodies to distinct Staphylococcus aureus antigens mutually neutralize opsonic killing and protection in mice. J Clin Invest 120: 3099-3102, 2010.

11 Brady RA, O’May GA, Leid JG, Prior ML, Costerton JW and Shirtliff ME: Resolution of Staphylococcus aureus biofilm infection using vaccination and antibiotic treatment. Infec Imm 79: 1797-1803, 2011.

12 Arciola CR, Campoccia D, Speziale P, Montanaro L and Costerton JW: Biofilm formation in staphylococcus implant infections. A review of molecular mechanisms and implications for biofilm-Resistant materials. Biomaterials 33: 5967-5982, 2012.

13 Søe NH, Vendel-Jensen N, Nürnberg BM, Jensen AL, Koch J, Poulsen SS, Pier GB and Johansen HK: A novel knee prosthesis Model of implant-related osteomyelitis in rats. Acta Orthopaedica Scand 84: 92-97, 2013

14 Gening ML, Maira-Litran T, Kropec A, Skurnik D, Grout M, Tsvetkov YE, Nifantiev NE and Pier GB: Synthetic $\beta-(1->6)-$ linked n-acetylated and nonacetylated oligoglucosamines used to produce conjugate vaccines for bacterial pathogens. Infect Immun 78: 764-772, 2010.

15 Cassat J, Dunman PM, Murphy E, Projan SJ, Beenken KE, Palm KJ, Yang S-J, Rice KC, Bayles KW and Smeltzer MS: Transcriptional profiling of Staphylococcus aureus clinical isolate and its isogenic agr and sarA mutants reveals global differences in comparison to the laboratory strain RN6390. Microbiology 152: 3075-3090, 2006.

16 Lucke M, Schmidmaier G, Sadoni S, Wildemann B, Schiller R, Stemberger A, Haas NP and Raschke M: A new model of implant-related osteomyelitis in rats. J Biomed Mater Res B Appl Biomater 67(1): 593-602, 2003.

17 Schmidmaier G, Lucke M, Wildemann B, Haas NP and Rascke M: Prophylaxes and treatment of implant-related infections by antibiotic-coated implants: a review. Injury 37: 105-112, 2006.

18 Høiby $\mathrm{N}$ and Frederiksen B: Microbiology of cystic fibrosis. In: Hodson ME, Geddes DM, editors. Cystic Fibrosis, 2nd edition. London: Arnold p. 83-107, 2000.
19 Matsumoto K, Nishi K, Kikuchi M, Kadowaki D, Tokutomi Y, Tokutomi N, Nishi K, Suenaga A and Otagiri: Alpha1-acid glycoprotein suppresses Rat acute inflammatory paw oedema through the inhibition of neutrophils activa-Tion and prostaglandin E2 generation. Biol Pharm Bull 30(7): 1226-1230, 2007.

20 Maira-Litran T, Kropec A, Abeygunawardana C, Joyce J, Mark III G, Goldmann DA and Pier GB: Immunochemical properties of the Staphylococcal poly-N-acetylglucosamine surface polysaccharide. Infect Immun 70: 4433-4440, 2002.

21 Cywes-Bentley C, Skurnik D, Zaidi T, Roux D, Deoliveira RB, Garrett WS, Lu X, O'Malley J, Kinzel K, Zaidi T, Rey A, Perrin C, Fichorova RN, Kayatani AK, Maira-Litran T, Gening ML, Tsvetkov YE, Nifantiev NE, Bakaletz LO, Pelton SI, Golenbock DT and Pier GB: Antibody to a conserved antigenic target is protective against diverse prokaryotic and eukaryotic pathogens. Proc Natl Acad Sci USA 110: E2209-2218, 2013.

22 Cerca N, Jefferson KK, Maira-Litran T, Pier DB, Kelly-Quintos C, Golmann DA, Azeredo J and Pier GB: Molecular basis for preferential protective efficacy of antibodies directed to the poorly acetylated form of staphylococcal poly-N-acetyl-beta (16)-glucosamine. Infect Immun 75: 3406-3413, 2007.

23 Latter SM, Llana MN, Denoël P, Germain S, Buzzola FR, Lee JC and Sordelli DO: Protein antigens increase the protective efficacy of a capsule-based vaccine against Staphylococcus aureus in a rat model of osteomyelitis. Infect Immun 82: 83-91, 2014.

24 Skurnik D, Kropec A, Roux D, Theilacker C, Huebner J and Pier GB: Natural antibodies in normal human sera inhibit Staphylococcus aureus capsular polysaccharide vaccine efficacy. Clin Infect Dis 55: 1188-1197, 2012.

25 Varrone JJ, de Mesy Bentley KL, Bello-Irizarry SN, Nishitani K, Mack S, Hunter JG, Kates SL, Daiss JL and Schwarz EM: Passive immunization with anti-glucosaminidase monoclonal antibodies protects mice from implant-associated osteomyelitis by mediating opsonophagocytosis of Staphylococcus aureus megaclusters. J Orthop Res 32(10): 1389-1396, 2014.

26 Vaudaux PE, Francois P, Proctor RA, McDevitt D, Foster TJ, Albrecht RM, Lew DP, Wabers $\mathrm{H}$ and Cooper SL: Use of adhesion-defective mutants of Staphylococcus aureus to define the role of specific plasma proteins in promoting bacterial adhesion to canine arteriovenous shunts. Infect Immun 63: 585-590, 1995.

27 Josefsson E, Hartford O, O’Brien L, Patti JM and Foster T: Protection against experimental Staphylococcus aureus arthritis by vaccination with clumping factor $\mathrm{A}$, a novel virulence determinant. J Infect Dis 184: 1572-1580, 2001.

28 Park J, Jagasia R, Kaufmann GF, Maghison JC, Ruiz DI, Moss JA, Meijler MM, Ulevitch RJ and Janda KD: Infection control by antibody disruption of bacterial quorum sensing signaling. Chem Biol 14: 1119-1127, 2007.

29 Otto M: Novel targeted immunotherapy approaches for staphylococcus infection. Expert Opin Biol Ther 10: 1049-1059, 2010.

Received October 13, 2016

Revised November 24, 2016

Accepted December 8, 2016 